\title{
La guerra como antítesis del derecho y la visión estatalista de la guerra civil Notas a propósito de la guerra civil colombiana de 1859-1862*
}

Recibido: 22/08/2020 | Revisado: 13/11/2020 | Aceptado: 23/11/2020

DOI: $10.17230 /$ co-herencia.18.34.11

\section{Sebastián Londoño-Sierra** \\ sebas.londono.s@gmail.com}

Resumen Con base en la propuesta de Norberto Bobbio en El problema de la guerra y las vías de la paz, de 1979, este artículo presenta una aproximación a la relación antitética entre la guerra y el derecho, es decir, aquella en que se considera la guerra como antítesis del derecho, en el contexto histórico de la guerra civil de 1859 a 1862 en la Confederación Granadina. El análisis teórico planteado, que remite a la visión estatalista y moderna de la guerra civil, se complementa con un componente histórico, por medio de un ejercicio de rastreo de sentidos de la mencionada relación antitética, en las cartas que, a propósito de algunos eventos de la guerra citada, intercambiaron el presidente Mariano Ospina y el general Tomás Cipriano de Mosquera.

Palabras clave: Guerra, guerra civil, soberanía, derecho, paz.

\section{War as the antithesis of law and the state's vision of civil war: Notes on the Colombian Civil War of 1859-1862}

\footnotetext{
Abstract Based on Norberto Bobbio's proposal in El problema de la guerra y las vías de la paz, this article presents an approach to the antithetical relationship between war and lawthat is, one in which war is considered the antithesis of law-in the historical context of the civil war from 1859 to 1862 in the Grenadian Confederation. The proposed theoretical analysis, which refers to the state and modern vision of the civil war, is complemented with a historical component by tracing the meanings of the aforementioned antithetical relationship in the letters that President Mariano Ospina and General Tomás Cipriano de Mosquera exchanged about some events of the civil war.
}

* Este artículo hace parte de la investigación $\mathrm{La}$ guerra como medio, objeto y antítesis del derecho. Una aproximación a la guerra civil de 1859-1862 en la Confederación Granadina.

** Magíster en Estudios Humanísticos. Director Técnico de la Dirección para la Construcción de Memoria Histórica, del Centro Nacional de Memoria Histórica. ORCID: 0000-0001$5615-7742$

\section{Keywords:}

War, civil war, sovereignty, law, peace. 
La soberanía es un alma artificial

que da vida y movimiento

al cuerpo entero, $[. .$.

la concordia, es la salud,

la sedición, la enfermedad,

la guerra civil, la muerte.

Hobbes

\section{Anotaciones preliminares}

Como lo dejan entrever y sugieren las anotaciones de los editores de la Revista Co-herencia en su invitación a publicar en este número, las relaciones que pueden configurarse entre la guerra y la paz son sumamente complejas, y cuánto más cuando el análisis debe refinarse para ingresar en lo que, en cierto sentido, puede ser la guerra civil, como parte de los confines de la guerra.

En la investigación con base en la cual este artículo se confecciona, se sostiene que nuevas lecturas pueden (re)surgir si, al pensar algunos asuntos relacionados con la guerra, se considera que "el concepto rector de 'orden público' tiende a cobijar bajo el derecho penal acciones que, bajo otra mirada, hacen parte del derecho de guerra" (Giraldo, 2015, pp. 15-16). Esto da cuenta de la proscripción de la guerra civil y, en consecuencia, su criminalización y la tipificación en la legislación penal de las conductas que la hacen efectiva y garantizan su despliegue.

Bajo este marco, es quizá esta publicación un lugar pertinente para insistir sobre trabajos filosófico-políticos que reivindiquen el cuestionamiento del consenso mayoritario, generando escenarios para un (re)surgir de lecturas alternativas ante la ausencia de una teoría de la guerra civil. Según Schnur, esta ausencia quizás indica que existe un tabú. Jorge Giraldo, por su parte, sostiene que "la guerra civil es la bestia negra del Estado moderno, y toda violencia organizada por fuera de la coacción estatal que garantiza la convivencia es inadmisible. El primer paso es el uso de los conceptos clásicos de guerra y guerra civil" (2009, p. 58). 
En El problema de la guerra y las vías de la paz (2008a [1979]), Norberto Bobbio propone que "hay por lo menos cuatro modos de considerar la relación entre guerra y derecho: la guerra como antítesis del derecho, como medio para realizar el derecho, como objeto del derecho y como fuente de derecho" (p. 95). En el marco de tal propuesta, este artículo ofrece una aproximación a una de esas posibles formas de ver la relación entre la guerra y el derecho: la guerra concebida como antítesis del derecho. Como puede haberse notado ya, el vínculo con los párrafos precedentes está dado, justamente, porque esta disposición antitética entre guerra y derecho está en la base y constituye el núcleo más duro de la modernidad estatal y del concepto de soberanía que la soporta, con la consecuente proscripción de la guerra civil.

Debe tenerse en cuenta que, en la propuesta de Bobbio sobre las cuatro relaciones, el concepto de guerra permanece, ${ }^{1}$ mientras la variación está dada por las distintas acepciones del término "derecho" (2008a, p. 95). Para los efectos de este artículo, baste con decir, al menos por el momento, ${ }^{2}$ que cuando se trata de la guerra como antítesis del derecho, este debe entenderse, según la teoría general del derecho, en un sentido objetivo o, lo que es equivalente, como el ordenamiento jurídico.

Las reflexiones que aquí se ofrecen parten, entonces, de un análisis teórico de la relación antitética entre la guerra y el derecho, en el contexto de la guerra civil colombiana de 1859-1862. Para esta contextualización, además de textos contemporáneos y de época que hacen referencia a los eventos de la guerra y la analizan desde muy diversas perspectivas, se tomó como base principal el intercambio epistolar que a propósito de los eventos de esa guerra llevaron a cabo el presidente Mariano Ospina Rodríguez y el general Tomás Cipriano de Mosquera, y que en esta ocasión se utiliza para resaltar y desarrollar la relación en que la guerra y el derecho aparecen enfrentados.

Asume Bobbio, coherente con su preferencia por las definiciones minimalistas, que la guerra es un conflicto entre grupos políticos respectivamente independientes o considerados tales, y cuya solución se confía a la violencia organizada (2008a, p. 162).

2 En la parte final, alguna mención se hará a la guerra como medio del derecho, y a propósito de la victoria de los rebeldes, se indicará la relación en que la guerra se presenta como fuente del derecho. 
Aunque las referencias a la legalidad, el orden y el ordenamiento jurídico se encuentran en la argumentación del gobernador del Estado del Cauca, el general Mosquera -como podrá verificarse en los fragmentos en que será citado-, los apartes aquí retomados remiten mayoritariamente a cartas escritas por el presidente de la Confederación, Don Mariano Ospina Rodríguez. Esto, por cuanto, según nuestros análisis, hacen referencias más explícitas al andamiaje teórico moderno en torno a la guerra como antítesis del derecho y a sus supuestos fundamentales. Es esta, por demás, una hipótesis verificada, ahora con menor sorpresa que al inicio de la investigación, teniendo en cuenta que al menos gran parte de las leyes de 1859, que fueron el "motivo de la discordia" (Uribe y López, 2008), se refiere a la intención de centralización y consolidación del poder del Gobierno general, como no puede ser de otra manera; y ello en detrimento de los poderes regionales y de los Estados, en lo que puede presentarse como un intento de remoción de intermediarios y la búsqueda de un ejercicio cada vez más directo del poder.

\section{Contexto mínimo acerca de la guerra civil colombiana de 1859-1862}

Para entender el contexto de las anotaciones teóricas aquí propuestas es pertinente afirmar que la guerra civil colombiana que se desarrolló entre los años 1859 y 1862 enfrentó al Gobierno general, en cabeza del presidente Mariano Ospina Rodríguez, con el bando liderado por el entonces Gobernador del Estado del Cauca, Tomás Cipriano de Mosquera. Se trató, en términos cronológicos, de una guerra con una fase de enfrentamientos regionales, otra de generalización del conflicto -es decir, de enfrentamientos con alcance nacional- y una de resistencia al gobierno revolucionario de Mosquera.

En la investigación de Uribe y López (2008), la particularidad de esta guerra en el marco de las guerras civiles del siglo XIX está dada por el resultado, los propósitos, los actores y las prácticas. A propósito, afirman las autoras:

Respecto de los resultados, ésta fue la única guerra del siglo XIX colombiano ganada por los rebeldes. El resultado revolucionario significó cambios 
sustanciales en el orden político, social, cultural y constitucional de la nación. En cuanto a los propósitos, la disputa estuvo centrada en la definición y los alcances de la soberanía, es decir, en las estrategias del poder central para ejercer efectivamente el dominio directo sobre todo el territorio y las resistencias de los Estados federales, encarnadas en sus intermediarios, para mantener el control político en sus regiones. Esta guerra no fue solamente una guerra por el régimen político -central o federal- sino, fundamentalmente, una guerra por el poder mismo bajo formas directas o indirectas de dominación (2008, p. 9).

Las discusiones jurídico-políticas que explican en gran medida esta guerra no se remiten solo a los debates relacionados con la expedición de la Constitución de 1858. Los antecedentes se remontan a las tensiones que, desde 1857, oponían la postura de los radicales, que pretendían ver cristalizada en la Constitución una asociación de Estados con las más amplias competencias, a la de los "legitimistas", ${ }^{3}$ cuya pretensión era la de un Ejecutivo de la Unión cada vez más fuerte, con atribuciones incluso sobre el orden público de los asociados (Gutiérrez, 2018).

Estas discusiones, confinadas en el nivel nacional al ámbito argumentativo, fueron concomitantes con enfrentamientos regionales armados y trascendieron para ingresar a la esfera de la acción política violenta, particularmente con ocasión de las leyes de 1859. Como se verá, estas leyes se erigen en "motivo de la discordia", como manifestación jurídica y política de la posición del gobierno conservador y expresión de la tensión entre sus posturas y las de los sectores liberales, que reivindicaban la soberanía de los Estados. ${ }^{4}$

3 No "centralistas", que parecía la denominación más probable, al menos como contraparte de la designación "federalistas", que asumieron los rebeldes. Para entender la manera en que se percibieron algunos de los más importantes eventos de la guerra desde una óptica conservadora, consultar las Narraciones contemporáneas de la guerra por la Federación en el Cauca (1859-1862), de Luis Ervin Prado y David Prado (2017). Esta remisión resulta de considerable utilidad para aproximarse a esta guerra desde una mirada regional -fundamental en este caso- y, sobre todo, por tratarse de un trabajo que recoge una compilación de textos de muy diversa naturaleza, que permiten confeccionar una visión de la guerra desde un círculo cercano a los hermanos Sergio y Julio Arboleda, con lo cual la lectura y reconstrucción de los hechos de la guerra se ve enriquecida desde el suroccidente de la Confederación Granadina.

4 Si bien el período federal inicia formalmente con la Constitución Política para la Confederación Granadina de 1858, hay que señalar la reforma constitucional del año 1855, que creó el Estado de Panamá y estableció la facultad para que el legislador erigiera en Estados porciones del territorio de la Nueva Granada. Con fundamento en esto, 
Debe tenerse en cuenta que las reflexiones y los acontecimientos que este trabajo referencia se dieron en el campo de una organización política donde las entidades territoriales eran más que autónomas para la gestión de ciertos asuntos. No se trataba de una República unitaria, a la manera en que se constituyó la organización política en $1843,{ }^{5} 1886^{6}$ o $1991,{ }^{7}$ por más descentralización y autonomía territorial y administrativa que se reconozca en estas tres formas de gobierno. Se trataba, como se declara en la Constitución de la Confederación Granadina de 1858, de Estados que se confederan a perpetuidad, y "el principio político sobre el cual se basa[n] es la subordinación del órgano central al poder de los estados" (Levi, 2008, p. 290). ${ }^{8}$

Ahora bien, es pertinente distinguir entre confederación y federación, procurando no desviar la atención del punto más importante para el análisis presente: la relación en que los Estados reivindican soberanía y acusan al Gobierno central de extralimitación

nacen el Estado de Antioquia en 1856, por disposición de la Ley del 5 de junio; y en 1857, los Estados de Santander, según la Ley del 13 de mayo; y Cauca, Cundinamarca, Boyacá, Bolívar y Magdalena, según la Ley del 15 de junio.

5 La Constitución de 1843 declara en su artículo 1, Título I: "La República de la Nueva Granada se compone de todos los granadinos unidos en cuerpo de nación, bajo un pacto de asociación política para su común utilidad".

6 La Constitución Política de 1886, en el artículo 1, Título 1, sentencia que "la Nación Colombiana se reconstituye en forma de República unitaria" (cursivas en el original). Nótese el énfasis que se hace al recurrir al verbo "reconstituir" -y no simplemente constituir- para señalar el quiebre con la Carta de 1863, que la antecede.

7 La Constitución Política de 1991, en el artículo 1, Título 1, consagra que "Colombia es un Estado social de derecho, organizado en forma de República unitaria, descentralizada, con autonomía de sus entidades territoriales" (cursivas en el original).

8 Se diferencia claramente de la "simple alianza", en la cual no surge "un órgano político de carácter diplomático compuesto por los representantes de los estados, que tiene la tarea de tomar las decisiones de interés común" (Levi, 2008, p. 290). Esta claridad en relación con la alianza es menor a la hora de distinguir la Confederación de la Federación, al menos tratándose del caso puntual de estudio, insistiendo en que la Constitución misma habla de "Estados que se confederan" y anticipando que Mosquera hablará explícitamente de "confederación" en algunos pasajes del intercambio epistolar. A pesar de ello, hablar de una organización política federal parece más ajustado, si se asume que "en las asociaciones entre estados dotados de órganos comunes existen algunas (las federaciones) cuyo funcionamiento se funda en una división de poderes entre estados miembros y gobiernos federales tal que cada uno es al mismo tiempo independiente y coordinado con los otros. [...] Existen otras (las confederaciones) cuyos órganos centrales, carentes de una autoridad propia y manteniendo la absoluta independencia de los estados asociados, no representan algo cualitativamente diferente a la suma de los entes políticos componentes" (Levi, 2008, p. 290). 
en el ejercicio de la Presidencia de la Confederación; y esta última, presidida por Ospina Rodríguez, acusa a los caudillos, líderes y gobernantes-militares liberales, autodenominados "republicanos", de ser fuente de perturbación del orden público, y de irrespeto y desconocimiento de las leyes.

Nuestro caso de estudio parece tratarse de algo más cercano a una federación, si se considera que "las decisiones de los órganos centrales de la confederación tienen más naturaleza de recomendaciones que de leyes" (Levi, 2008, p. 291), pero en 1858 se proclamó que los Estados se someterían "a las decisiones del Gobierno general, en los términos que se establecen en esta Constitución [la del 58]". Además, "las confederaciones no tienen un gobierno democrático. Sus órganos emanan de los gobiernos o de los parlamentos de los estados" (Levi, 2008, p. 291), mientras que en el artículo 60 de la Carta del 58 no queda duda al respecto: "El Presidente de la Confederación será elegido por el voto directo de los ciudadanos de ella".

Si bien el artículo décimo de la Constitución de 1858 incluye una imposición según la cual "las autoridades de cada uno de los Estados tienen el deber de cumplir y hacer que se cumplan y ejecuten en él la Constitución y las leyes de la Confederación, los decretos y órdenes del Presidente de ella, y los mandamientos de los Tribunales y Juzgados nacionales", el artículo octavo consagra una disposición, a la manera de cláusula residual de competencia, en donde sentencia que "todos los objetos que no sean atribuidos por esta Constitución a los poderes de la Confederación, son de la competencia de los Estados".

9 La complejidad y profundidad del debate en torno a la soberanía, cuando de una organización federal se trata, rebasa la pretensión de este artículo. Las menciones al asunto permiten resaltar, simplemente, una característica central de la Nueva Granada en la primera parte de la segunda mitad del siglo XIX. Solo para sugerir la dimensión del asunto, resulta ilustrativo Hermann Heller (1995 [1927]), quien, en debate con Georg Jellinek, recuerda que la peculiaridad del Estado es la de ser una unidad decisoria universal para un territorio determinado y su soberanía reside justamente en ello, y sobre esta asunción no es posible "aceptar que sobre un mismo territorio existan dos unidades decisorias supremas; su existencia significaría la destrucción de la unidad del estado y su consecuencia sería el estallido de la guerra civil" (p. 214). Sin embargo -y este es el punto del debate-, Heller resalta: "Este concepto del estado no demandaría nuevas explicaciones si no fuese porque el análisis de la naturaleza del estado federal condujo, desde mediados del siglo pasado, a una nueva doctrina del estado, contradictoria con las ideas que venimos sustentando: nos referimos a la tesis, ampliamente generalizada, del estado no-soberano" (1995, p. 214). 
En 1859 se llevó a cabo un ejercicio legislativo que permitió concretar el debate en un terreno con implicaciones prácticas, en un contexto histórico determinado. Aquel año se reunió el Congreso y dentro de su producción normativa resaltan las leyes del 8 de abril, "sobre elecciones"; del 10 de mayo, "que organiza la hacienda nacional"; y del 12 de mayo, "sobre organización e inspección de la fuerza pública en los estados". En estas leyes se consagraron regulaciones o figuras que implicaban, en mayor o menor medida, la intervención del Gobierno general en asuntos que a los ojos de algunos Estados eran de su competencia; considerándolas, en consecuencia, inconstitucionales, entre otras cosas, por la vulneración de la autonomía y soberanía inspiradas en el pacto de asociación, cristalizado en la Constitución..$^{10}$

El asunto de la delimitación de las competencias de los Estados y el Gobierno general no es, ni mucho menos, un tema jurídico de segundo orden y sus implicaciones políticas se dejan ver con nitidez. En muchos asuntos jurídicos, y más tratándose de derecho constitucional, lo político y lo jurídico se imbrican y complementan necesariamente, dando lugar a discusiones jurídicas colindantes con la teoría política. En este caso, la dimensión del debate se nota en la carta que dirigió Mosquera, el 13 de noviembre de 1859, desde Popayán, en respuesta a la que desde Bogotá había remitido el presidente Ospina el 12 de octubre de 1859. Los términos del general caucano son los siguientes:

10 Para dar algo de claridad en relación con la naturaleza de las leyes en disputa se mencionan algunos ejemplos. En la Ley sobre elecciones, se anota que "para el efecto de hacer las elecciones nacionales, se dividen los estados de la Confederación en círculos, y éstos en distritos electorales". En materia de organización de la hacienda, vale la pena retomar el Decreto del 30 de julio, que daba condiciones para la mayor y más directa presencia del Gobierno general en los Estados, al decretar en su artículo $1^{\circ}$ que "cada uno de los estados de Antioquia, Bolívar, Boyacá, Cauca, Cundinamarca, Magdalena, Panamá y Santander formarán un distrito de hacienda, regido por un intendente, excepto el de Panamá, que lo será por el intendente general, establecido allí por la ley del 26 de junio de 1857". En lo relativo a la organización de la fuerza pública, los artículos 2 y 3 de la Ley del 12 de mayo estipulan que "corresponde al Gobierno general la suprema inspección de la fuerza pública municipal de los estados; y cuando esté a disposición del Gobierno general, debe el Poder Ejecutivo reorganizarla como mejor convenga al servicio a que se le destina, pudiendo nombrar libremente los jefes y oficiales". Y en el artículo 3 se lee: "Para que el Gobierno general pueda desempeñar este deber, nombrará para cada estado inspector, que podrá ser un general, o jefe del ejército de la Confederación". 
Supone U. que cuando yo cité a U. el pacto de unión violado, quise decir Constitución. El pacto es el artículo $1^{\circ}$ de la Constitución que dice: "Los Estados de Antioquia, Bolívar, Boyacá, Cauca, Cundinamarca, Magdalena, Panamá y Santander, se confederan a perpetuidad, forman una Nación soberana, libre e independiente bajo la denominación de "Confederación Granadina," y se someten a las decisiones del Gobierno general en los términos que se establecen en esta Constitución". "Este solo artículo es un pacto de unión [...] Esto es lo que se llama un pacto, -alianza y unión entre soberanos. Los Estados se reservaron expresamente para gobernar todo lo que no delegaron; y por tanto, el Gobierno general rompe y viola el pacto si no cumple con obrar en la esfera que se le ha trazado en los artículos que dejo enumerados. Las demás disposiciones son propiamente la Constitución u organización del Gobierno general, y el desarrollo de los diez y seis artículos principales. He hablado con propiedad; pero la sutileza de hacerme una suposición, de que pacto quiere decir Constitución, no es muy sencilla; y encierra en sí una negativa de donde parten las usurpaciones, que U. como Presidente propuso al Congreso y que esa Corporación aprobó por actos legislativos, nulos en cuanto han violado el pacto de unión. ${ }^{12}$

En el reproche de Mosquera, el lenguaje jurídico deja filtrar asuntos políticos de las más altas dimensiones, como es el de la soberanía. Vale la pena, en este punto, hacer dos anotaciones: la primera, referida a la horizontalidad de la interlocución; y la segunda, relacionada con el carácter regional o local que impone matices a la configuración estatal.

En cuanto a lo primero, nótese que, tratándose de una organización política federal, este debate configura una interlocución política y jurídica horizontal en no pocos asuntos, pues las entidades territoriales, aunque en un marco de competencias constitucionalmente delimitado, eran Estados en el estricto sentido del término. En lo que respecta al segundo punto, como lo reseña Manuel Alonso, los factores subyacentes y que explican ese talante regional y local son variados, y se originan en procesos complejamente reposados, cuyos antecedentes se hallan en el orden colonial:

1 Cursivas en el original.

12 Toda la correspondencia citada entre Mariano Ospina Rodríguez y Tomás Cipriano de Mosquera fue extraída de la Correspondencia entre el General Tomás Cipriano de Mosquera y el Doctor Mariano Ospina Rodríguez, Fondo Pineda de la Biblioteca Nacional de Colombia, Tomo 340, Pieza 19. 
El acotamiento de la autoridad política del Estado a partir de lo municipal y local, el carácter 'profundamente localista y provinciano de la aristocracia criolla' y el aislamiento entre las distintas regiones geográficas, permanece, se inserta y se aloja en el nuevo Estado republicano, y posibilita la configuración de un ensamblaje de lo estatal marcado por la presencia de fuertes localismos y regionalismo, y una profunda fragmentación de los territorios y el poder político [...] (Alonso, 2014, pp. 177-178).

En este contexto histórico, esbozado en un par de elementos relevantes, es en donde se analiza aquella relación en la cual la guerra es la negación del derecho y el derecho se instituye como aquel que culmina la guerra o, en términos casi equivalentes, instaura la paz. Como ya se mencionó y como se verá más adelante, se trata de una relación que es consecuencia necesaria de la modernidad política, de su inescindible y constitutiva asunción del concepto de soberanía y de la centralidad que le otorga a la organización política estatal.

Sin lugar a dudas, en el marco de la guerra del 59 al 63, una de las mayores victorias para los legitimistas fue "la inmortal batalla del Oratorio [que] se dio en el alto de este nombre el 18 de agosto", como recuerda Don Felipe Pérez en Anales de la revolución (1862, p. 416). En esta batalla fue sometido el gobierno seccional de Santander, "laboratorio del radicalismo", fueron detenidos sus dirigentes y se les confiscó el armamento.

Por lo que simbolizó la victoria del Oratorio, es factible afirmar que los observadores afectos al Gobierno general creyeron que los vientos les eran favorables para vencer, si se reconoce lo que representaba entonces el Estado de Santander y se da credibilidad a los relatos de la época, dentro de los cuales referimos Cómo se evapora un ejército (1901), del intelectual y militar conservador Don Ángel Cuervo:

El recibimiento fue espléndido, como los que se hacían al Libertador en la Gran Colombia: desde Ubaté hasta la puerta de palacio no se veían sino arcos triunfales, ventanas enfestonadas y flores regadas por el suelo. Las caballerías de la Sabana unidas a cuatrocientos húsares que acompañaban al Presidente, e innumerables jinetes de Bogotá y de los pueblos circunvecinos formaban un tropel no imaginado antes en la ciudad. El entusiasmo rayaba en frenesí, y dondequiera que se mostraba una cara era para vitorearle o arrojarle flores. Ovación que casi hacía presentir un calvario. En medio de este triunfo arrebatador iba D. Mariano Ospina a caballo con vestido de 
viaje y con la sencillez de un filósofo: contestaba los vítores y felicitaciones con esa sonrisa apacible que le era peculiar, y la satisfacción interior apenas se traslucía en la placidez del semblante (1901, p. 49).

Pese a esta victoria, al final de la guerra se verifica el triunfo definitivo de Mosquera y los radicales, al tomar Bogotá en 1861. Recuérdese que esto constituye una de las particularidades de esta confrontación en el inventario de las guerras civiles colombianas, por tratarse de la única ganada por los rebeldes. Así, por efecto del triunfo de la violencia organizada, el entonces delincuente y sublevado se transmutó en gobernante y, en este caso, la revolución se cristalizó en la Constitución de Rionegro de $1863 ;^{13}$ ante la mirada abatida de quienes vieron en la génesis de los eventos solo un arrebato casi feudal de un gran señor del Cauca, que decidió enfrentar al Gobierno general, sin muchas perspectivas de éxito. Felipe Pérez (1862) retoma una comunicación de Julián Trujillo del 20 de julio de 1861 para, desde la perspectiva del bando federalista, dar cuenta de lo ocurrido:

Si el valor y bizarría han lucido en el ejército a la vista de todos los habitantes de la capital, no ha sido menos laudable la disciplina y moderación con que el ejército tomó la ciudad, dirigiéndose los jefes principales a la cárcel, a poner en libertad a los Magistrados, jefes, oficiales, soldados y simples ciudadanos que, en número de más de 500, estaban hacinados en una inmunda prisión. La población en masa saludaba a sus libertadores, y el partido conservador vencido, no oyó ni un solo "muera" ni una palabra ofensiva de 4.500 vencedores, y de una población embriagada con el placer que produce el triunfo de la libertad [...] Ocupada la capital de los Estados Unidos, está organizado el Gobierno general en ella, y mañana se posesionarán los ministros de la Corte Suprema (1862, pp. 632-633).

Teniendo en cuenta el talante de Don Mariano Ospina en la Presidencia del Gobierno general, la tendencia a la centralización de las leyes de 1859 y lo que la guerra al interior de la organización

13 Aunque la revolución y posterior Constitución de 1863 no se trata en este artículo más allá de esta mención, sí remite necesariamente a otra de las relaciones entre guerra y derecho propuestas por Bobbio (2008a), a saber, aquella en que la guerra se erige en fuente del derecho. Se trató de una revolución que instauró un nuevo ordenamiento jurídico, que derogó por la fuerza al que lo antecedía. Siguiendo a Bobbio, "para la teoría del derecho, la revolución significa el momento de ruptura entre un orden y otro, la terminación, que jurídicamente quiere decir invalidez e ineficacia, del viejo orden, y el comienzo del nuevo" (2009, p. 646). 
política podría haber significado, especialmente desde la perspectiva de la Presidencia de la Confederación, vale la pena insistir en lo irreconciliable que suele resultar la guerra civil con el marco que impone la estatalidad moderna y su modelo de génesis europea. Las implicaciones teóricas, que tratándose de la guerra siempre tienen consecuencias en la praxis política, son recogidas por Giraldo:

Esta es la idea original y perenne de la guerra civil: la guerra que produce la civitas o que se lleva a cabo a su interior. La guerra civil es la más antigua y se quiere que sea la más anacrónica, pues la civitas excluiría su existencia. Toda la filosofía política (y el pensamiento político, en general) ha recogido esta tradición, pues la guerra civil existe sólo como antesala de la instauración del Estado o amenaza eventual e indeseada contra él. Pensando con el deseo, la filosofía se ha marginado tradicionalmente de la guerra civil como objeto de trabajo y ha compartido esta carencia con las disciplinas sociales (Giraldo, 2001, pp. 191-192).

Sin embargo, en este texto y en particular para el análisis de la relación antitética entre guerra y derecho, se retoma el sentido resultante de disponer estos conceptos en el marco del Estado moderno, resultante de la consolidación del poder absoluto y soberano que pone fin a las guerras civiles confesionales, silenciando el ruido de las espadas privadas.

\section{La crítica estatalista a la guerra civil}

Como ya se dijo, conforme a la propuesta analítica de Norberto Bobbio (2008a), uno de los cuatro modos en que se puede considerar la relación entre guerra y derecho es aquella en que se disponen antitéticamente; es decir, en donde la guerra es la negación del derecho y, en su contracara, el derecho se revela como aquel que termina la guerra o instaura la paz.

Se trata de una relación que, a los ojos de muchos juristas y teóricos de la política, se muestra obvia en principio (su dicotomía permanece absoluta y totalmente comprensible para algunos, incluso hoy).${ }^{14}$ No debe olvidarse, sin embargo, que la inmediatez

14 La persistencia de la guerra civil y su mayor importancia relativa entre los fenómenos de la violencia organizada contemporánea demandan romper, como se mencionó antes, el 
y automaticidad con que se asume que la guerra es la antítesis del derecho es consecuencia necesaria de la modernidad política, y su inescindible y constitutiva asunción del concepto de soberanía. No puede ser de otro modo, ya que, en sentido moderno, la soberanía alude al "alma" de ese dios mortal que es el Estado y, en términos de Thomas Hobbes ${ }^{15}$ representa la creación artística más trascendental del hombre, pues

en efecto: gracias al arte se crea ese gran Leviatán que llamamos república o Estado (en latín civitas) que no es sino un hombre artificial, aunque de mayor estatura y robustez que el natural para cuya protección y defensa fue instituido; y en el cual la soberanía es un alma artificial que da vida y movimiento al cuerpo entero (Hobbes, 2006, p. 3).

Ahora bien, en términos modernos no se trata, simplemente, de un "alma" que mueve ciertas funciones accesorias o mecánicas, ni de la apelación a una simple metáfora ontológica. Se trata del motor constitutivo, de la potencia primera y última del Estado, siempre como acción, nunca como latencia; en concordancia con Bobbio, en su Teoría general de la política (2009), citando a Bodin: "Por soberanía se entiende el poder absoluto y perpetuo que es propio del Estado" (p. 153).

El carácter absoluto del poder remite necesariamente a la estatalidad. Retomando los planteamientos de Max Weber, de la mano de Bobbio, se puede afirmar que

El monopolio de la fuerza o el uso exclusivo del poder coactivo es condición necesaria para la existencia del Estado, porque un Estado puede renunciar al monopolio del poder ideológico [...]; puede renunciar al monopolio del poder económico [...]. Pero no puede renunciar al monopolio del poder coercitivo sin dejar de ser Estado. La desmonopolización del poder coercitivo representaría simple y sencillamente el retorno al estado de naturaleza hobbesiano (Bobbio, 2009, p. 149).

tabú conforme al cual la guerra civil no es más que "la bestia negra del Estado moderno" (Giraldo, 2001 y 2009).

15 Recuérdese la anotación de Hobbes al respecto de la formación del Estado como pacto de cada hombre con los demás: "Esta es la generación de aquel gran Leviatán, o más bien (hablando con más reverencia), de aquel dios mortal, al cual debemos, bajo el Dios inmortal, nuestra paz y nuestra defensa" (2006, p. 141). 
Por la vía de la remoción de intermediarios y un ejercicio cada vez más directo del poder, a través de burocracias propias, se verifica un proceso por medio del cual se va configurando el Estado como realidad política, que elimina el imperio medieval y el reino eclesiástico, de manera que la modernidad sucede al ordenamiento político estamental propio de la Edad Media.

Debe tenerse en cuenta que el flujo de Europa a América era importante en materia intelectual y las élites incorporaban en su repertorio los andamiajes que partían del Viejo continente. No obstante, como lo han mostrado las profesoras Uribe y López en La guerra por las soberanías (2008), mientras uno de los rasgos centrales del proceso de formación de los Estados nacionales europeos fue la desaparición de las formas de dominio indirecto y la creciente instauración de un Estado centralizado y homogéneo, en Colombia las formas de dominación indirecta no fueron una etapa previa, transicional y anómala de la construcción del Estado nacional, sino una vía diferente de ese proceso de formación. En Colombia, los dominios indirectos no estarían destinados necesariamente a desaparecer cuando el Estado centralizado estuviese instaurado, sino que permanecerían por largo tiempo (2008, p. 46).

Es por esto por lo que, superado el ordenamiento medieval, para mediados del siglo XIX ya ese carácter absoluto del poder había mostrado rostros muy definidos, conocidos en profundidad por los gobernantes, militares y la intelectualidad granadina. En nuestro caso concreto, esto queda claro en la discusión en torno a las características soberanas y la defensa de la legalidad (argumento esgrimido por ambos bandos). Por ejemplo, el 13 de noviembre, desde Popayán, el Gobernador del Cauca dirigió una carta a Ospina Rodríguez, en franco reproche y denunciando el tono que advertía en el presidente de la Confederación:

¿Cuál otro sería el lenguaje de Francisco José, Emperador de Austria, creyéndose el representante de la soberanía nacional de aquel imperio? Cuál otro fue el lenguaje de Fernando VII y sus agentes durante los diez y seis años de la guerra de la independencia en América? ${ }^{16}$

Vale la pena señalar desde ya que este fragmento permite establecer una relación con la guerra como medio para reestablecer el derecho, al ambientar la discusión en torno a la 
El proceso que se ha referido en el caso europeo, por el cual se desemboca en el ejercicio directo del poder y se consolida la organización política como estatal, no puede presentarse como copia facsimilar para el caso granadino. Como se enunció en la primera parte, no se pueden dejar de lado la fragmentación regional y local del poder en el período histórico que nos ocupa, y "la presencia y peso de lo municipal, provincial y local en la definición territorial de la autoridad estatal" (Alonso, 2014, p. 176), con la consecuente tensión que ello implicaba. Como claramente queda planteado en una carta escrita por el general Ramón Espina, "el problema de la autonomía era el del poder regional de los círculos dominantes, mucho más importante para ellos en cuanto más concreto y posible de ejercer que un difuso poder nacional" (Citado por Tirado, 1995, p. 15).

En términos de Uribe y López (2008), la guerra civil de 1859-1862 escenificó la lucha por las soberanías, pues en ella la supremacía del Estado central fue puesta en vilo, disputada, resistida, negociada y desplazada por actores con capacidad de conservar para sí recursos de fuerza y también legales e institucionales, para decidir y controlar la vida social y política de los territorios y localidades donde actuaban:

En la Confederación Granadina de mediados del siglo XIX, la disputa por el establecimiento de formas de control directas o indirectas de dominación no va del Estado hacia la sociedad, la cual sería articulada a un poder centralizado, concentrado, único e indivisible, tal como lo describe Tilly para Europa; tampoco se trata de un Leviatán poderoso que logra expropiar a sus rivales de los recursos de poder, como lo presenta Weber, sino de un conflicto que se despliega dentro del corpus institucional, burocrático y legal de un Estado que, si bien se manifiesta como inorgánico y de fronteras difusas, ya está constituido con amplia capacidad de acción para la configuración del orden político (2008, p. 47).

El de la concentración progresiva de poder es un proceso que resulta ser, si se quiere, definitorio. A decir de Norbert Elias, "sólo con la constitución de este monopolio permanente del poder central

justa causa, a la injuria, sugiriendo rostros dictatoriales o al menos absolutistas. Se trata de términos y fundamentos también retomados por el general Mosquera para responder al presidente Ospina, en su pretensión de dejar clara la legitimidad para acudir a las armas, en el análisis que involucra el juicio adjetivo en torno a la justicia de la guerra; es decir, acerca de si la guerra es justa o injusta. 
y de este aparato especializado de dominación, alcanzan las unidades políticas el carácter de Estados" (2009, p. 414). La verificación del ejercicio exclusivo de la fuerza legítima y del recaudo -los monopolios de la violencia y del fisco-, a través de un aparato administrativo propio, permanente y especializado, constituye el núcleo más duro del Estado como organización política y realidad históricamente determinada. ${ }^{17}$

Ahora bien, si se citó a Bodin respecto a la soberanía como poder absoluto y supremo, que promueve el tránsito de la Edad Media a la modernidad, por medio del surgimiento del Estado soberano -definiendo simultáneamente el interior y el exterior de sus fronteras-, no se puede dejar de hacer una referencia más detenida al "primer razonamiento filosófico sistemático acerca de la nueva entidad llamada Estado, contenido en el Leviathan, de TomÁs HobBes" (Schmitt, 2002, p. 152).

No es una simple anécdota que en Excaptivitate salus. Experiencias de la época 1945-1947, una obra muy personal de Carl Schmitt (escrita en el cautiverio, bajo arresto automático en el marco de la segunda guerra mundial), a cuyo lector ruega que la lea "como si fueran una serie de cartas a él personalmente dirigidas", este pensador afirme:

En mi vecindad más próxima, cotidiana, se hallan otros dos, que han fundado el derecho internacional partiendo del derecho político: Jean Bodin y Thomas Hobbes. Estos dos nombres de la época de las guerras civiles confesionales han llegado a ser para mí nombres de personas vivas y presentes, nombres de hermanos, con los cuales he emparentado por encima de los siglos. [...] En este momento no tengo más que mi memoria. Pero los pensamientos y formulaciones de ambos me son tan familiares como el modo de pensar y hablar de un hermano (2010 [1950], pp. 60-61).

Ese primer razonamiento sobre el Estado aparece en el libro de Hobbes, con la referencia plástica a la metáfora viva del Leviatán,

17 Vale la pena aclarar que en la reconstrucción propuesta por Elias, en el denominado "mecanismo del monopolio", el poder central está cimentado, a la vez, sobre el monopolio del poder militar y del poder fiscal, como sigue: "Los medios financieros que afluyen así a este poder central sostienen el monopolio de la violencia; y el monopolio de la violencia sostiene el monopolio fiscal. Ambos son simultáneos; el monopolio financiero no es previo al militar y el militar no es previo al financiero, sino que se trata de dos caras de la misma organización monopolística" (Elias, 2009, p. 414). 
que representa, por medio de un animal, el poder más fuerte de la tierra. Su poder y potencia es tal que, como señala Schmitt:

Ni la entraña del texto, ni la historia del vocablo, ni la recta ilación sistemática conceptual, ni la lógica montada al aire de la historia de las ideas, pueden decir la última palabra cuando se ventila nada menos que el destino político de una imagen mítica. El nombre Leviathan es uno de esos nombres míticos que no se pueden citar en vano, y es tan fuerte su imagen, que, aun pintada en la pared, empieza a operar por su cuenta (2004, p. 47).

$\mathrm{Al}$ respecto, también vale la pena recuperar parte de la descripción que ofrece Job en el Antiguo Testamento, pues ilustra suficientemente la dimensión del poder que debe erigirse justo allí donde se quiere huir de la miserable condición de guerra de todos contra todos, en la que "existe continuo temor y peligro de muerte violenta; y la vida del hombre es solitaria, pobre, tosca, embrutecida y breve" (Hobbes, 2006, p. 103):

¿Quién de los mortales le quitará a Leviatán la piel que lo cubre? ¿O quién entrará en su espantosa boca? / Su cuerpo es impenetrable como los escudos fundidos de bronce, y está apiñado de escamas entre sí apretadas. / [...] / Cuando estornuda, parece que arroja chispas de fuego, y sus ojos centellean como los arreboles de la aurora. / De su boca salen llamas como de tizones encendidos. / Sus narices arrojan humo como la olla hirviente entre llamas. / Su aliento enciende los carbones, y su boca despide llamaradas. / En su cerviz reside la fortaleza; y va delante de él la miseria. / [...] / Cuando él se levanta sobre las olas tienen miedo los ángeles mismos, y amedrentados procuran purificarse y aplacar al cielo. / Si alguno quiere embestirlo, no sirven contra él ni espada, ni lanza, ni coraza; / pues el hierro es para él como paja y el bronce como leño podrido. / [...] / Con sus bufidos hará hervir el mar profundo como una olla, y hará que se parezca al caldero de ungüentos, cuando hierve a borbollones. / [...] / En fin, no hay poder sobre la tierra que pueda comparársele, pues fue criado para no tener temor de nadie. / Mira debajo de sí cuanto hay de grande, como quien es el rey de todos los más soberbios animales (Sagrada Biblia, 1959, Job 40: 13-40).

Tal es y debe ser el poder del Estado, pues responde nada menos que a la necesidad de garantizar la seguridad de todos, su paz y defensa, y es así que, por temor y miedo, los individuos se someten al poder común. La inconmensurabilidad del poder instituido está dada por la autoridad que le confiere cada individuo, y "posee y 
utiliza tanto poder y fortaleza, que por el terror que inspira es capaz de conformar las voluntades de todos ellos para la paz, en su propio país, y para la mutua ayuda contra sus enemigos, en el extranjero" (Hobbes, 2006, p. 141).

Se considera entonces definida la entidad política Estado cuando, territorialmente, con fronteras más o menos claras, es posible identificar el adentro ("en su propio país") y el afuera del mismo ("en el extranjero") y, en ese sentido, los ámbitos interno y externo del ejercicio del poder soberano, es decir, respectivamente, las soberanías "inmanente" y "transeúnte" (Madiedo, 1874). Con esta realidad histórica que se configura en el suelo europeo y la progresiva formación de las fronteras interestatales que se establecen entre los monopolios eficaces y "legítimos" de la violencia, se consolida simultáneamente la identificación o asimilación del interior de la organización política como pacificada (López, 2007).

Recuérdese que en la guerra civil de 1859-1862, que enfrentó al Gobierno general presidido por Mariano Ospina y a los Estados que conformaron el bando liderado por el Gobernador del Cauca, se estaba en presencia de un régimen federal, puntualmente, la Confederación Granadina, con los ocho Estados que la componían. Teniendo en cuenta esto en el análisis de la relación antitética de la guerra y el derecho, y también la pacificación que supone y constituye la entidad estatal, se entiende el reproche que elevó el presidente Ospina, respondiendo al general Tomás Cipriano de Mosquera, en carta fechada el 12 de octubre de 1859:

Mi estimado Señor y General. Los Estados, aun suponiéndolos soberanos, pueden ser tan perturbadores del orden general como las provincias, los departamentos, los distritos, los individuos. Perturbar el orden, es estorbar el cumplimiento de las leyes y el ejercicio de la autoridad, que es lo que constituye el orden; y como el cumplimiento de las leyes y el ejercicio de la autoridad, lo mismo pueden ser estorbados por la acción de un Estado entero que por la de una fracción de él o por una cuadrilla de conspiradores, la calificación de perturbadores es aplicable lo mismo al Estado que a la pandilla.

Como consecuencia del proceso que -en el caso europeo- progresivamente configuró la entidad estatal y en virtud de la implementa- 
ción del ordenamiento jurídico en el territorio comprendido dentro de sus fronteras, se desconoce el "derecho de resistencia" y se criminaliza a todo aquel que enfrente al Estado, pues "en la modernidad política, el primer blanco de la promulgación son los competidores de la soberanía absoluta, de tal modo que la proscripción de la guerra se producirá contra la guerra interna, en primer lugar" (Giraldo, 2009, p. 51). En el mismo sentido, frente a las reivindicaciones de los Estados que cuestionaban el proceder del Gobierno general de Ospina y ante la tensión que permitía intuir un momento ante bellum, el presidente de la Confederación complementaba su exposición, en la misma carta del 12 de octubre, advirtiendo a Mosquera su falta de legitimidad para acudir a las armas y la consecuente imposición del derecho interno, incluso por medio de la fuerza:

Si hubiere quién levantare la bandera de la rebelión resistiendo de hecho la Constitución o las leyes, el Poder Ejecutivo no tiene para qué deliberar en la materia, lo que en tal caso debe hacer está claramente escrito en la misma Constitución y en las mismas leyes, empleará la fuerza pública de la Confederación y la de los Estados contra los perturbadores del orden; no para disolver Estados ni para cambiar gobiernos, ni para hacer que se sobreponga este partido o el otro, sino para hacer ejecutar y cumplir esa Constitución y esas leyes generales, y por consiguiente para hacer juzgar y castigar a los que las hubieren violado.

Al interior de las fronteras, de acuerdo con esta carta, el Estado se identifica con la pacificación, la seguridad y el orden, como si se tratara de un proceso progresivo en que las características que va adquiriendo el Estado lo acercan a una situación de paz -ausencia de guerra-. No obstante, este es un asunto casi de definición y, en cierta medida, autorreferente, pues la guerra civil se asume como incompatible con el Estado. En un fragmento que deja entrever la diferencia que en torno al derecho de resistencia lo aleja de su maestro, Carl Schmitt es contundente en la negación y condena de la guerra civil:

O el Estado existe realmente como tal Estado y funciona como instrumento incontrastable de la paz, de la seguridad y del orden, y tiene de su parte el derecho objetivo y el derecho subjetivo, puesto que como legislador único y supremo crea él mismo todo el derecho, o no existe realmente y no cumple 
su función de asegurar la paz. Entonces no hay Estado, sino estado de naturaleza. Puede ocurrir que el Estado deje de funcionar y que la gran máquina quede rota por la rebelión y la guerra civil. Pero esto no tiene nada que ver con el "derecho de resistencia". Si se admitiera este derecho dentro del Estado de Hobbes, sería tanto como admitir un derecho a la guerra civil reconocido por el Estado, es decir, un derecho a destruir el Estado; por consiguiente, un absurdo. El Estado pone término a la guerra civil. Lo que no pone término a la guerra civil no es un Estado. Lo uno excluye lo otro (2004, pp. 41-42). ${ }^{18}$

No debe olvidarse que a la ordenación del suelo europeo como configuración de Estados en términos modernos precedieron las guerras civiles confesionales, cruentas y muy duraderas, de los siglos XVI y XVII. Parece haber un consenso en "que el Leviatán es el gran Estado moderno que nace de las cenizas de la sociedad medieval" (López, 2007, p. 40), lo cual resulta ser de trascendental importancia para entender el carácter absoluto de la soberanía, en el sentido promulgado por los teóricos del derecho político europeo. Por esta vía, es necesario regresar a Bodin, de quien Carl Schmitt decía:

De su fuerte deseo de neutralidad pública, seguridad y orden nacen en su cabeza los primeros conceptos jurídicamente claros del derecho político europeo. [...] Ha expuesto con incomparable acierto el concepto decisivo del jus publicum Europaeum, el Estado soberano en política interior y exterior. Es uno de los parteros del estado moderno (2010, pp. 61-62).

\section{Con Hobbes, esa soberanía bodina se encarna explícitamente en} el Estado, persona instituida para garantizar la paz y el bien común, al que, como soberano, entre otras atribuciones, le corresponde determinar los medios para lograr el fin, ${ }^{19}$ sin que cualquier otro

18 En un análisis del caso colombiano, en similar sentido, Iván Orozco Abad afirma: "De la misma manera que el Estado es la negación de la guerra civil, la guerra civil es también, en cualquier tiempo, la negación del Estado y, lo que en el contexto de esta discusión resulta tanto o más importante, el Estado, como monopolio de la violencia, es la condición de posibilidad de la vida democrática" (2006, p. 16).

19 Sostiene el filósofo de Malmesbury: "Como el fin de esta institución es la paz y la defensa de todos, y como quien tiene derecho al fin lo tiene también a los medios, corresponde de derecho a cualquier hombre o asamblea que tiene la soberanía, ser juez, a un mismo tiempo, de los medios de paz y de defensa, y juzgar también acerca de los obstáculos e impedimentos que se oponen a los mismos, así como hacer cualquier cosa que considere necesario, ya sea por anticipado, para conservar la paz y la seguridad, evitando la discordia en el propio país y la hostilidad del extranjero, ya, cuando la paz y la seguridad 
pueda justamente acusarlo o castigarlo. La esencia del Estado es la de una persona de cuyos actos una gran multitud, por pactos mutuos, realizados entre sí, ha sido instituida por cada uno como autor, al objeto de que pueda utilizar la fortaleza y medio de todos, como juzgue oportuno, para asegurar la paz y defensa común. El titular de esta persona se denomina SOBERANO, y se dice que tiene poder soberano; cada uno de los que le rodean es SúBDiTo suyo (Hobbes, 2006, p. 141).

Para Schmitt, en El concepto de lo político (2009), el hecho de que el Estado como unidad política determinante declare la guerra y disponga de la vida de las personas es trascendente, ${ }^{20} \mathrm{e}$ insiste en que

la aportación de un Estado normal consiste sobre todo en producir dentro del Estado y su territorio una pacificación completa, esto es, en procurar "paz, seguridad y orden" y crear así una situación normal que constituye el presupuesto necesario para que las normas jurídicas puedan tener vigencia en general (2009, p. 75).

Así las cosas, de la mano de los ius publicistas modernos se van entretejiendo relaciones fuertemente anudadas entre "paz", "seguridad", "orden" y, cómo no, "normalidad" con "derecho" en sentido objetivo, resaltando de paso el papel protagónico que ante la situación de excepción asume el derecho penal.

Como lo señala Don Mariano Ospina Rodríguez de manera diáfana y contundente, con el ropaje descriptivo que le es propio y suponiendo las condiciones soberanas indiscutibles que su dignidad presidencial representa:

El Gobierno general no declara guerra al Estado, ni al distrito, ni al individuo. Cuando se resiste el cumplimiento de la ley, el Gobierno dispone que se juzgue a los que hacen la resistencia: si estos cesan en ella y se someten voluntariamente al juicio y al castigo, todo está terminado, el Gobierno no tiene más que hacer; pero si persistiesen en la comisión del delito, si pretenden sustraerse por la fuerza al juicio y a la pena, entonces el

se han perdido, para la recuperación de la misma" (Hobbes, 2006, p. 145).

20 En palabras de Schmitt, ello es consecuencia del ejercicio de la "competencia aterradora" de declarar la guerra, que tiene el Estado como unidad política determinante, "pues el ius belli implica tal capacidad de disposición: significa la doble posibilidad de requerir por una parte de los miembros del propio pueblo la disponibilidad para matar y ser muertos, y por la otra de matar a las personas que se encuentran del lado enemigo" (2009, p. 75). 
Gobierno usa de la fuerza, no para debelarlos como beligerantes armados, sino para desarmarlos y aprehenderlos como reos, a quienes tiene que poner a disposición del juez respectivo. Aquí no hay declaratoria de guerra ni cosa parecida.

En relación con el caso de la guerra civil que se sella con la Constitución de 1863, este asunto que registra Schmitt permite recordar que, por el carácter federal del régimen y la mayor disposición de recursos con que cuentan las partes, el derecho es primordial. Y es que el derecho, como ordenamiento jurídico válido, es un dispositivo de inevitable aplicación ante la resistencia violenta al cumplimiento de las leyes, constituyéndose como defensa insalvable de la eficacia del ordenamiento mismo. ${ }^{21}$ Todo ello bajo la lógica moderna que asume "la realidad ineluctable de que el Estado es, no solo en el momento de su origen histórico, sino siempre, la negación de la guerra civil" (Orozco, 2006, p. 11).

En este sentido, y asumiendo que las leyes de 1859 tenían en su conjunto la vocación de limitar los poderes de aquellos que, desde la óptica del Gobierno central, eran intermediarios, el presidente Ospina respondía al general Mosquera:

Pienso como U. que es inútil que el país se ensangriente con la guerra civil, y no solamente que es inútil, sino que es muy ruinoso y muy deplorable. ¿Pero cómo es que se evita que el país se ensangriente con la guerra civil? Respetando todas las leyes, absteniéndose de vías de hecho, buscando la enmienda o la reforma de lo que juzguen irregular o pernicioso por los medios legales. Si los Gobiernos de los Estados y los particulares siguen tal camino, debe U. estar perfectamente seguro de que el país no será ensangrentado con la guerra civil. Pero si alguno, sea gobernante o sea particular resistiese el cumplimiento de las leyes generales o pretendiere por vías de hecho sobreponer su voluntad al querer de la Nación legalmente expresado; el Gobierno general, teniendo el deber estricto e imprescindible de hacer ejecutar y cumplir esas leyes, no dejará de hacerlo, y si se resistiese el cumplimiento con las armas, con las armas lo hará efectivo, porque esto es lo que las leyes ordenan, y lo que en todas las naciones civilizadas del mundo se ejecuta y debe ejecutarse.

Para avanzar hacia las relaciones entre la guerra y el derecho, el

21 Téngase en cuenta la diferencia entre validez y eficacia del derecho, pero, a la vez, su complementariedad, en la forma en que ambas se disponen en este planteamiento. 
retorno a Bobbio es, una vez más, clarificador. En el inicio del ensayo "Paz y derecho" (2009), la antítesis guerra-derecho se introduce así:

La primera configuración de la guerra que nos sale al paso desde una tradición de siglos es la de la causa eficiente de un estado antijurídico; por el contrario, la primera y más antigua configuración del derecho es la de causa eficiente de un estado de paz. En otras palabras, la guerra se concibe primariamente como negación del derecho, y el derecho, a su vez, como afirmación o reafirmación de la paz (2009, pp. 605-606).

Esta disposición de la guerra como desorden y el derecho como orden se profundiza en la medida en que, en la organización estatal, la paz se concibe como finalidad del ordenamiento jurídico.

Hay debates profusos y controvertidos en torno a la paz como valor y fin único o último del derecho objetivo. Sin embargo, parece más probable construir consensos en torno a la paz como fin mínimo del ordenamiento jurídico, es decir, la paz como ausencia de guerra (Bobbio, 2008a, p. 97; 2008b, p. 453).22 En este punto es necesario insistir en que la pacificación del territorio que constituirá y permitirá delimitar geográficamente el Estado se garantiza también por medio del derecho, en el marco de un proceso en donde, recurriendo al uso de la violencia, se somete progresivamente a actores -privados- que ejercen poder y se les sobrepone un poder tal que da lugar al Estado, como organización política históricamente determinada.

Por esta vía, el vínculo entre el derecho y la paz se hace cada vez más indisoluble, en una relación bidireccional que se torna casi circular; dando cuenta de la asimilación mutua según la cual el derecho está al servicio de la paz y la paz, una vez perturbada, se restablece con el derecho; incluso por medio del recurso último a su antítesis, la guerra. Así, además, emerge algo aparentemente contradictorio: el objetivo de la guerra es la paz o el restablecimiento del derecho. ${ }^{23}$ De esta manera, sutilmente y tras el velo solemne del

22 Acerca del contenido del Estado en la propuesta de Kelsen, Mario Montoya afirma: "El Estado por sí mismo carece de un contenido determinado, es sólo una forma de producir Derecho. De ahí que Kelsen niegue, en general, todo contenido asignado al Estado: ni la homogeneidad del pueblo, ni algún telos histórico, ni un vínculo espiritual de los ciudadanos, ni la propiedad, la paz o la igualdad. Mucho menos la libertad" (2011, p. 120).

23 El desarrollo en relación con este asunto invita al análisis de la relación entre guerra y derecho, donde aquella es "guerra justa" y este es "derecho subjetivo", pues es en 
triunfo de la legalidad, reposa como recurso posible y consecuente la guerra. Esto se evidencia en una contestación del presidente Ospina ante la pormenorizada exposición de Mosquera en carta previa, procurando disuadir o anticipando el desconocimiento violento del ordenamiento jurídico:

La Nación, pues, está altamente interesada en primer lugar en que la paz se conserve y en segundo lugar en que triunfe el principio de la legalidad si la paz se turbare. Es natural, pues, que todos los hombres de sentido común que no especulen con la guerra o con la anarquía estén dispuestos a coadyuvar a la conservación de la paz, y, siendo esta turbada, al triunfo de la legalidad.

Derecho, legalidad, orden, seguridad y paz son conceptos que irradian e inspiran toda la respuesta del presidente conservador, proponiendo relaciones que, en algunos casos, los hacen términos intercambiables, si bien no como sinónimos, sí como expresiones con un sentido convergente. Volviendo al caso de la discusión prebélica que se confeccionó a finales de la década del 50 del siglo XIX colombiano (en donde unos consideraban competencias del Gobierno general lo que otros veían como desconocimiento de la soberanía de los Estados), la línea argumentativa de Ospina puede ser una muestra de la convergencia de sentido antes señalada:

La representación nacional debe tener completa libertad para deliberar en los negocios de su competencia, para aceptar o desechar las pretensiones de uno o más Estados, según que las estime justas o injustas sin dejarse imponer por preparativos bélicos, ni por amenazas de insurrección ni de

esos términos en los que propiamente se puede hablar de la guerra como reparadora o restablecedora del derecho. En este artículo no puede sino mencionarse el tema: la denominada teoría de la guerra justa comprende, con las variaciones y desarrollos de varios siglos, una doctrina moral dirigida a delimitar los contornos de la legitimidad de la guerra, es decir, a justificar la guerra (Santiago, 2001). Así, dado que se trata de contornos delimitados, como lo sostiene Giraldo, "las teorías de la guerra justa hacen parte de las posturas ético-políticas denominadas 'relativistas', que 'se distancian de posturas excepcionales en la historia y el pensamiento, como el belicismo absoluto y el pacifismo absoluto', avocando por la fijación de parámetros para justificar algunas guerras" (2009, p. 179). En términos que muy probablemente ofrezcan mayor claridad, sobre todo por lo arraigados en el lenguaje filosófico, recuérdese que cuando se hace referencia a la guerra justa se trata del juicio de carácter adjetivo sobre la guerra, conforme al cual se dice de la guerra que es justa o injusta: es el juicio sobre la agresión y la legítima defensa o, lo que es lo mismo, el ius ad bellum, retomando el lenguaje de los autores medievales (Walzer, 2001, p. 51). 
separación, de otra manera el principio de la justicia y de la legalidad quedaría reemplazado por el de la fuerza; la Confederación sería regida no por la voluntad de la mayoría constitucionalmente expresada, sino por el poder tiránico de las bayonetas $i$ de las lanzas; al sistema de la paz sucedería el de la guerra, y al orden y a la seguridad la anarquí.. ${ }^{24}$

Finalmente, en este artículo se han propuesto elementos que contribuyen a entender la relación en que el derecho y la guerra se enfrentan, se oponen y se excluyen. Tomando aquí el derecho como derecho objetivo, es decir, en su acepción de ordenamiento jurídico, y al que subyace la noción de orden social como pacificación y legalidad, especialmente al interior de las fronteras estatales.

La idea es cara a la modernidad política, y quizá ello explica que, tanto en los argumentos de Mariano Ospina como de Tomás Cipriano de Mosquera, aparezcan el orden y el respeto de la legalidad. En el caso del presidente, aunque hace difícil no pensar en la intención de remoción de intermediarios en procura de un ejercicio cada vez más directo del poder, lo que se lee es una defensa férrea del ordenamiento jurídico y las leyes promulgadas en 1859, "motivo de la discordia", anunciando el consecuente uso de la fuerza para garantizar la eficacia del derecho, en caso de ser necesario. En lo que constituye esencialmente un debate hermenéutico-jurídico, igual ocurre con el general caucano, cuya argumentación discurre también por la vía de la defensa del derecho y el orden constitucional que consagró la Confederación, aunque dejando entrever el recurso a la guerra como medio para la restauración del derecho vulnerado, señalando así el debate en torno a la justicia de la guerra.

La argumentación de Mosquera sugiere un tránsito sutil entre la guerra como antítesis y la guerra como medio del derecho, en lo que sin duda es una línea de investigación fructífera, pero, no siendo posible abordarla aquí, se retoma nuevamente el desarrollo de Norberto Bobbio, desde la Teoría general de la política, para concluir con la claridad del filósofo italiano las reflexiones en torno a la relación antitética entre guerra y derecho:

$\overline{24}$ Cursivas en el original. 
Una vez reconocida la guerra como legibus soluta, es decir, más allá de cualquier posibilidad de control jurídico, la guerra se convierte en una fuerza primigenia que allí donde aparece derrumba el mundo del derecho. Se vuelve así a una concepción tradicional, clásica de la guerra: inter arma silere leges. En este punto interviene la concepción del derecho como conjunto de normas ordenadas al fin de la paz; y la paz es la eliminación de la guerra. Allí donde avanza el reino del derecho, cesa el estado de guerra. Más aún, la victoria del derecho consiste en la gradual eliminación de las relaciones de fuerza desregulada en que consiste la guerra; y, por tanto, a su vez, el derecho es la antítesis de la guerra (2009, p. 604)【

\section{Referencias}

Alonso, M. (2014, julio-diciembre). Ensamblajes institucionales y guerras civiles en la Colombia del siglo XIX. Co-herencia, 11(21), 169-190.

Bobbio, N. (2008a [1979]). El problema de la guerra y las vías de la paz. Gedisa.

Bobbio, N. (2008b). Derecho. En N. Bobbio, N. Mateucci y G. Pasquino (Dirs.), Diccionario de Política. Siglo XxI.

Bobbio, N. (2009). Teoría general de la política. Trotta.

Cuervo, Á. (1901). Cómo se evapora un ejército. Recuerdos personales de la campaña que concluyó el 18 de julio de 1861 con la toma de Bogotá por los revolucionarios. Editor Jorge Roa.

Elias, N. (2009). El proceso de la civilización. Investigaciones sociogenéticas y psicogenéticas. Fondo de Cultura Económica.

Giraldo, J. (2001). El rastro de Caín. Guerra, paz y guerra civil. Foro Nacional por Colombia.

Giraldo, J. (2009). Guerra civil posmoderna. Siglo del Hombre Editores, Instituto de Filosofía Política de la Universidad de Antioquia y Fondo Editorial Universidad Eafit.

Giraldo, J. (2015). Política y guerra sin compasión. En Comisión Histórica del Conflicto y sus Víctimas, Contribución al entendimiento del conflicto armado en Colombia. Comisión Histórica del Conflicto y sus Víctimas.

Gutiérrez, D. (2018). Una paz plagada de guerras, 1863-1876. En C. Camacho, M. Garrido y D. Gutiérrez (Eds.), Paz en la República: 
Colombia, siglo XIX. Universidad Externado de Colombia.

Heller, H. (1995 [1927]). La soberanía. Contribución a la Teoría del Derecho estatal $v$ del Derecho internacional (2. ${ }^{\text {a }}$ ed). Universidad Nacional Autónoma de México.

Hobbes, T. (2006). Leviatán: o la materia, forma y poder de una república eclesiástica y civil. Fondo de Cultura Económica.

Levi, L. (2008). Confederación. En N. Bobbio, N. Mateucci y G. Pasquino (Dirs.), Diccionario de Política. Siglo XXI.

López, L. (2007). Las ataduras de la libertad. Autoridad, igualdad y derechos. Fondo Editorial Universidad Eafit.

Madiedo, M. M. (1874). Tratado de derecho de gentes, internacional, diplomático y consular. Tipografía de Nicolás Pontón y Compañía.

Montoya, M. (2011). El concepto de libertad en la obra de Hans Kelsen. En M. Montoya y N. Montoya (Eds.), Hans Kelsen. El reto contemporáneo de sus ideas políticas. Fondo Editorial Universidad Eafit.

Orozco, I. (2006). Combatientes, rebeldes y terroristas. Guerra y derecho en Colombia. Temis.

Pérez, F. (1862). Anales de la revolución, escritos según sus propios documentos. Imprenta del Estado de Cundinamarca.

Prado, L. E. y Prado, D. (2017). Narraciones contemporáneas de la guerra por la Federación en el Cauca (1859-1863). Transcripción, estudio preliminar y notas críticas. Universidad del Rosario.

Sagrada Biblia (Traducida de la vulgata latina al español) (1959). Sopena.

Santiago, T. (2001). Justificar la guerra. Universidad Autónoma Metropolitana, Porrúa.

Schmitt, C. (2002). El nomos de la tierra en el Derecho de Gentes del "Ius publicum europeaum". Comares.

Schmitt, C. (2004). El Leviathan en la teoría del Estado de Tomas Hobbes. Comares.

Schmitt, C. (2009). El concepto de lo político. Alianza.

Schmitt, C. (2010 [1950]). Ex captivitate salus. Experiencias de la época 19451947. Trotta. 
Tirado, Á. (1995). Aspectos sociales de las guerras civiles en Colombia. Gobernación de Antioquia.

Uribe, M. T. y López, L. (2008a). La guerra por las soberanías. Memorias y relatos en la guerra civil de 1859-1862 en Colombia. La Carreta Editores, Universidad de Antioquia.

Walzer, M. (2001). Guerras justas e injustas. Un razonamiento moral con ejemplos históricos. Paidós.

\section{Archivo}

Correspondencia entre el General Tomás Cipriano de Mosquera y el Doctor Mariano Ospina Rodríguez. Biblioteca Nacional de Colombia. Fondo Pineda. Tomo 340, Pieza 19.

\section{Normas}

Constitución Política 1 de la República de Nueva Granada de 1843 (8 de mayo de 1843).

Constitución Política para la Confederación Granadina de 1858 (22 de mayo de 1858).

Constitución Política de los Estados Unidos de Colombia de 1863 (8 de mayo de 1863).

Constitución Política de la República de Colombia de 1886 (5 de agosto de 1886).

Constitución Política de Colombia (20 de julio de 1991). Gaceta Constitucional, (116).

Ley de 5 de junio de 1856. Por la cual el Congreso decreta que se erija "el Estado federal de Antioquia, compuesto de la actual provincia de ese mismo nombre".

Ley de 13 de mayo de 1857. Por la cual se crea el Estado de Santander.

Ley de 15 junio de 1857. Que erige en "Estados federales y partes integrantes de la Nueva Granada" los Estados de Cundinamarca, Boyacá, Cauca, Magdalena, Bolívar. 
Ley de 8 de abril de 1859. "Sobre elecciones".

Ley de 10 de mayo de 1859. "Que organiza la hacienda nacional".

Ley de 12 de mayo de 1859. "Sobre organización e inspección de la fuerza pública en los Estados”.

Presidente de la Confederación. Decreto de 30 de julio de 1859, "En ejecución de la ley de 10 de mayo último, por el cual se organiza la hacienda nacional". 